\title{
Phase-Angle Balance Control for Harmonic Filtering of a Three-Phase Shunt Active Filter System
}

\author{
Souvik Chattopadhyay and V. Ramanarayanan
}

\begin{abstract}
This paper proposes a new strategy for harmonic filtering of a three-phase shunt active filter system. The shunt harmonic filter's control objective is defined as: balance the phase angle of the input current with the phase angle of the line frequency component of the load current. This objective is achieved in digital implementation without sensing the input voltages. The controller uses a phase-shifting method on the sensed input current and then applies the resistor-emulator-type input-current-shaping strategy on the phase-shifted current. In implementation, Texas Instrument's digital-signal-processor-based unit TMS320F240 EVM is used as the digital hardware platform. The control algorithm is computationally simple yet the harmonic filtering performance is high. The analysis, simulation, and experimental results of a threephase shunt active filter prototype on a 25-A nonlinear load are presented.
\end{abstract}

Index Terms-Digital-signal-processor (DSP) TMS320F240based implementation, harmonic filter, phase-angle balance (PAB) control, shunt active filter (SAF), voltage-sensorless operation.

\section{INTRODUCTION}

$\mathbf{T}$ HE shunt active filter (SAF) is a current-controlled voltage-source converter (VSC) of boost topology. We can identify two major functions in the control of shunt active filter. First, it must generate a current reference containing only those components of harmonic current that are present in the load, and second, a very high bandwidth current controller, that would extract the same actual current waveshape as dictated by the reference, needs to be implemented. The design of a high-bandwidth current controller is important but not the unique feature of active filter control. The unique feature of active filter control is the method of harmonic extraction. The method should be such that each harmonic component in the reference is exactly equal in magnitude and phase to the corresponding harmonic component in the load current. It is difficult though to design a harmonic filter that would separate out the fundamental from the lower order harmonics without any phase shift. As a result, conventional filtering technique

Paper IPCSD 02-076, presented at the 2000 IEEE Applied Power Electronics Conference and Exposition, New Orleans, LA, February 6-10, and approved for publication in the IEEE TRANSACTIONS ON INDUSTRY APPLICATIONS by the Industrial Power Converter Committee of the IEEE Industry Applications Society. Manuscript submitted for review December 1, 2001 and released for publication December 17, 2002.

S. Chattopadhyay was with the Power Electronics Group Department of Electrical Engineering, Indian Institute of Science, Bangalore 560012, India. He is now with the Department of Electronics and Communication Engineering, Jalpaiguri Government Engineering College, Jalpaiguri 735102, India (e-mail: souvik_ee_iisc@yahoo.co.in).

V. Ramanarayanan is with the Power Electronics Group Department of Electrical Engineering, Indian Institute of Science, Bangalore 560012, India (e-mail vram@ee.iisc.ernet.in).

Digital Object Identifier 10.1109/TIA.2003.808941

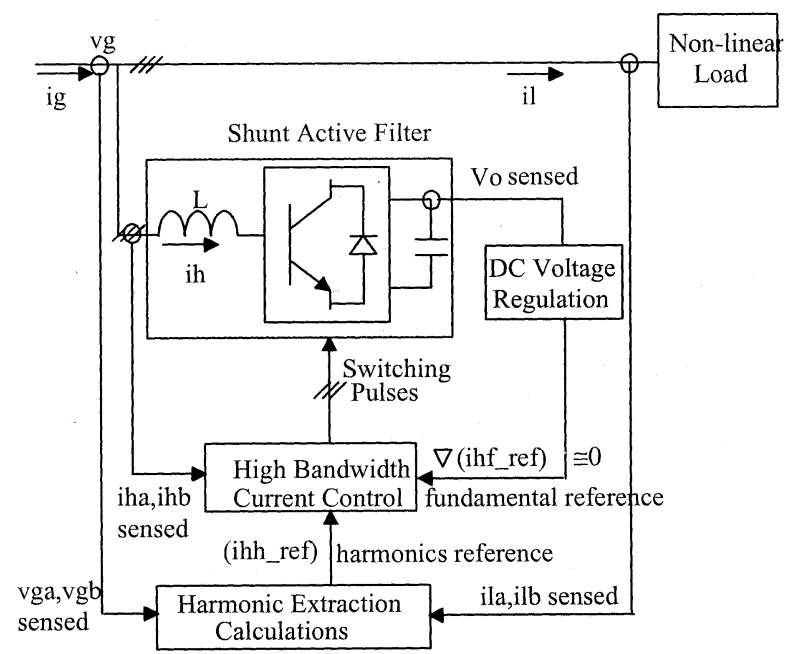

Fig. 1. Block diagram of the existing control methods.

can not be applied in a straightforward manner. Moreover, there can be unbalanced currents in the phases that may also have to be filtered out from the input. The harmonic extraction theories that have addressed these issues and provided implementable solutions are: 1) the instantaneous active and reactive power method [2]; 2) the synchronous reference frame method [3]; and 3) the instantaneous active and reactive current component method [4].

All these methods involve computations using the sensed input voltage. A block diagram of the existing control methods is shown in Fig. 1. It shows that two voltage sensors are required for sensing the input voltages. However, the input voltage waveform of a real life system can have distortions. Therefore, to filter out the distortions in the input voltage, a phase-locked loop (PLL) circuit is a mandatory requirement for these methods. Design of a high-performance PLL is not easy. It is a computational burden on the digital controller as well.

This paper proposes a new strategy, named here as the phase angle balance (PAB) control, for filtering the harmonic currents of a three-phase shunt active filter system. The schematic diagram is shown in Fig. 2. The control objective of a shunt active filter is defined in this method as: balance the phase angle of the input current with the phase angle of the line-frequency component of the load current. This objective is achieved in digital implementation without sensing the input voltage. PAB control has the ability to compensate only for the harmonics of the load current. Under such condition, the reactive component of the load current is supplied by the input and the SAF works like an impedance emulator. However, if required, PAB can be used to 


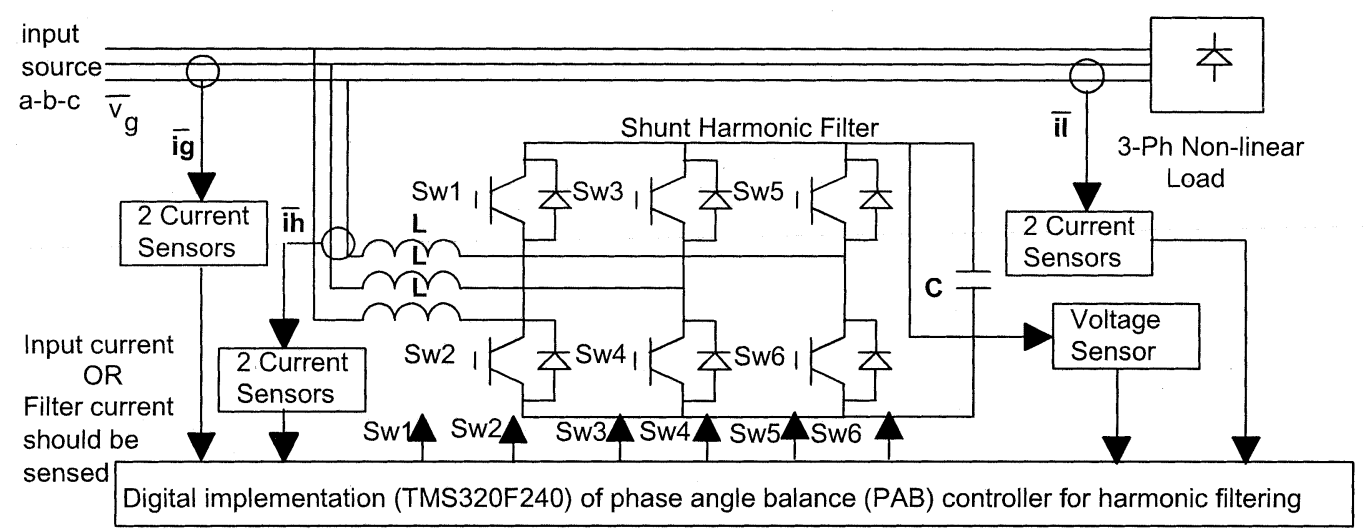

Fig. 2. Schematic diagram of a three-phase shunt active filter system with the proposed controller.

compensate for both the harmonics as well as the reactive component of the load current. When the SAF is operated with the above objective it effectively makes the nonlinear load appear as a resistance to the input source. The active filtering strategy proposed in [5] is not available with such flexibility.

A few power-factor-correction (PFC) strategies have been proposed that do not use input voltage sensors. The virtual flux direct power control (VF-DPC) [6] is structurally similar to the well-known direct torque control (DTC). The switching frequency of the VF-DPC is not constant and the sampling frequency needs to be much higher than the switching frequency. The digital implementation requires fast $\mathrm{A} / \mathrm{D}$ converters and microprocessors. In comparison, the current-mode control technique of PAB is based on constant switching frequency and low sampling frequency. It can be implemented using low-speed digital hardware such as digital signal processor (DSP) TMS320F240 (20 MHz 6.6 $\mu$ s ADC. The input voltage sensorless method proposed in [7] has the structure of a voltage-oriented control (VOC). In comparison, the input current shaping is performed in $\mathrm{PAB}$ with a much simpler control structure. In this method, coordinate transformation is not required. There are no current error amplifiers in the control loop. This method has eliminated the need for observers that are required in [7] for estimation of the input voltages.

In Section II, we have explained the basic principle of operation of the proposed PAB controller. Two methods for the determination of the phase shift of the input current are also provided. The simulation results of the proposed control scheme are presented in Section III. The voltage-sensorless digital implementation strategy specific to the TMS320F240 controller is given in Section IV. In Section V, the experimental results of the prototype shunt active filter system are presented.

\section{PAB CONTROL}

The PAB control is proposed to filter the harmonics of a threephase SAF system. It is an extension of the current-shaping method described in [1] that shapes the input current like input voltage for high power factor operation of boost rectifier. The difference is that the PAB control makes the phase-shifted input current proportional to the input voltage. The control objective for a three-phase shunt active filter, defined in Fig. 3, is to make the input current $\overline{i_{g}}$ devoid of higher order harmonics that are

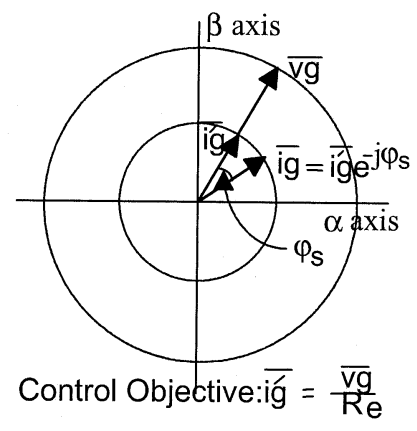

Fig. 3. Control objective of a three-phase shunt active filter.

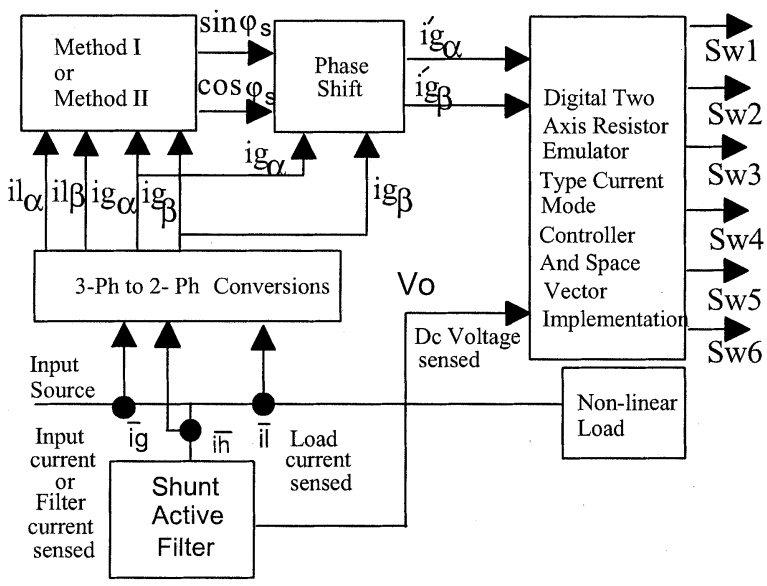

Fig. 4. Block diagram of the PAB control technique.

otherwise present in load current $\overline{i_{l}}$. In order to keep the rating of the active filter low, current in the shunt filter $\overline{i_{h}}$ should contain only the harmonic currents but not the reactive current of the load.

The reactive component of the load current has to be supplied from the input side. Mathematically, the function of the shunt active filter can be expressed as

$$
\overline{i_{g}}=\frac{\overline{v_{g}}}{R_{e}} e^{-j \varphi_{s}}
$$

where $\overline{i_{g}}$ and $\overline{v_{g}}$ are input current and voltage vectors, respectively. $\varphi_{s}$ can be positive or negative depending on whether the load is inductive or capacitive, respectively. $R_{e}$ is the emulator 


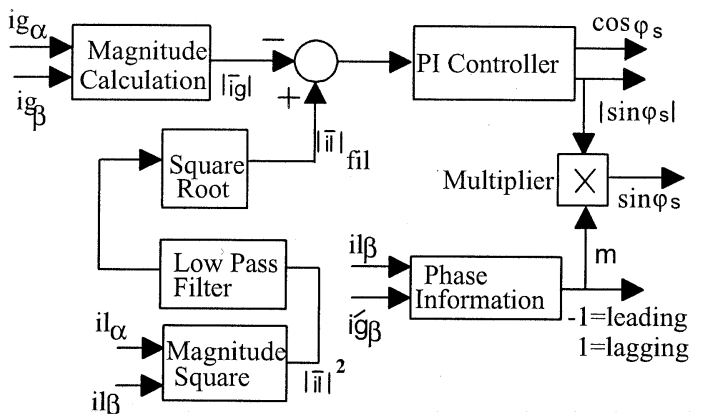

(a)

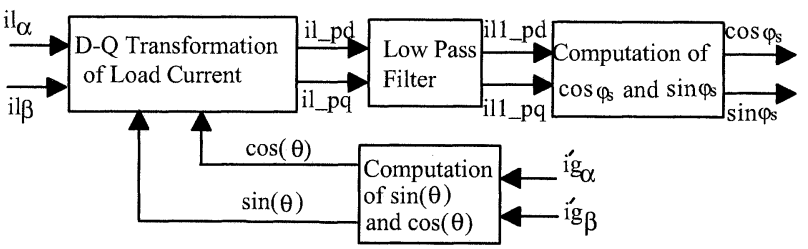

(b)

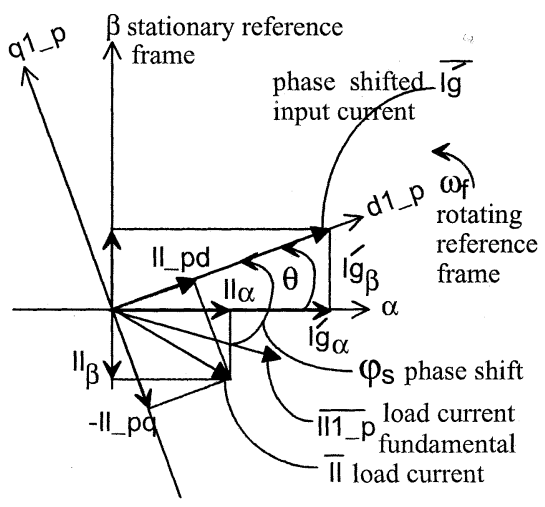

(c)

Fig. 5. (a) Determination of $\sin \left(\varphi_{s}\right)$ and $\cos \left(\varphi_{s}\right)$ by Method I. (b) Determination of $\sin \left(\varphi_{s}\right)$ and $\cos \left(\varphi_{s}\right)$ by Method II. (c) Load current space phasors $\left(\overline{i_{l}}\right)$, $\left(\overline{i_{l 1 \_p}}\right)$ in stationary $(a, \beta)$ and rotating $\left(d 1_{-} p, q 1_{-} p\right)$ reference frame.

resistance corresponding to active power transfer in the positive direction. The required phase shift depends on the load power factor. In implementation, either the input current can be sensed directly or obtained by summation of the load and the filter currents. For determination of the phase shift, load current needs to be sensed.

Let us assume that the input voltage $\left(v_{g}\right)$ is sinusoidal and balanced

$$
\overline{v_{g}}=v_{g a}+j v_{g \beta}=V_{g 1} \cos \left(\omega_{f} t\right)+j V_{g 1} \sin \left(\omega_{f} t\right)
$$

where $\omega_{f}$ is the angular frequency of the input voltage. $(a, \beta)$ is a system of orthogonal and stationary axes as shown in Fig. 3. The variables with suffix $a$ or $\beta$ represent components along that particular axis. A line-current-shaping controller, similar to the one that has been described in [1] for high-power-factor operation of a three-phase boost rectifier, can be used here to make $\left(\overline{i_{g}^{\prime}}\right)$ proportional to $\left(\overline{\nu_{g}}\right)$ It has been shown in Fig. 3 that from the input current $\left(\overline{i_{g}}\right),\left(\overline{i_{g}^{\prime}}\right)$ can be obtained by phase shifting by an angle $\varphi_{s}$ Therefore,

$$
\begin{aligned}
\overline{i_{g}^{\prime}}= & i_{g a}^{\prime}+j i_{g \beta}^{\prime}=I_{g 1} e^{j\left(\omega_{f} t\right)}=\overline{i_{g}} e^{j \varphi_{s}} \\
= & i_{g a} \cos \left(\varphi_{s}\right)-i_{g \beta} \sin \left(\varphi_{s}\right) \\
& +j\left(i_{g \beta} \cos \left(\varphi_{s}\right)+i_{g a} \sin \left(\varphi_{s}\right)\right)
\end{aligned}
$$

where

$$
\overline{i_{g}}=i_{g a}+j i_{g \beta}=I_{g 1} e^{j\left(\omega_{f} t-\varphi_{s}\right)} .
$$

It can be noted that if we make the phase shift $\varphi_{s}$ equal to the phase angle of the positive-sequence component of the fundamental frequency load current then the input current will consist only of active and reactive current components of line frequency.
This general principle of filtering the harmonic currents is denoted here as the PAB control technique. The block diagram of the PAB controller is given in Fig. 4. We can use either Method I, shown in Fig. 5(a) or Method II, shown in Fig. 5(b), to get the desired phase angle $\varphi_{s}$.

Method I: For a three-phase three-wire system (i.e., no zerosequence current), the nonlinear load current $\left(\overline{i_{l}}\right)$ can be expressed as a summation of harmonics of positive-sequence and negative-sequence current components. It has been assumed that there is no dc component in the load current

$$
\overline{i_{l}}=\sum_{k=1}^{\infty}\left(\overline{i_{l k \_p}}+\overline{i_{l k \_n}}\right)
$$

where $k$ is the harmonic number.

In the suffix of a variable " $p$ "and " $n$ " indicate positive- and negative-sequence components, respectively. The space phasors in the above equation are decomposed into $(a, \beta)$ axis components as given by (6) and (7)

$$
\begin{aligned}
i_{l a}= & \sum_{k=1}^{\infty} i_{l k a}=\sum_{k=1}^{\infty} i_{l k a_{-} p}+\sum_{k=1}^{\infty} i_{l k a_{-} n} \\
= & \sum_{k=1}^{\infty}\left(I_{l k_{-} p} \cos \left(k \omega_{f} t+\varphi_{k_{-} p}\right)\right. \\
& \left.+I_{l k_{-} n} \cos \left(-k \omega_{f} t+\varphi_{k_{-} n}\right)\right) \\
i_{l \beta}= & \sum_{k=1}^{\infty} i_{l k \beta}=\sum_{k=1}^{\infty} i_{l k \beta_{-} p}+\sum_{k=1}^{\infty} i_{l k \beta \_n} \\
= & \sum_{k=1}^{\infty}\left(I_{l k_{-} p} \sin \left(k \omega_{f} t+\varphi_{k_{-} p}\right)\right. \\
& \left.+I_{l k_{-} n} \sin \left(-k \omega_{f} t+\varphi_{k_{-} n}\right)\right) .
\end{aligned}
$$




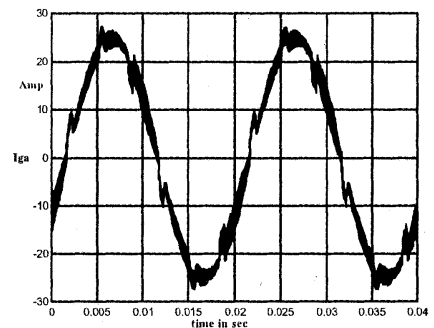

(a)

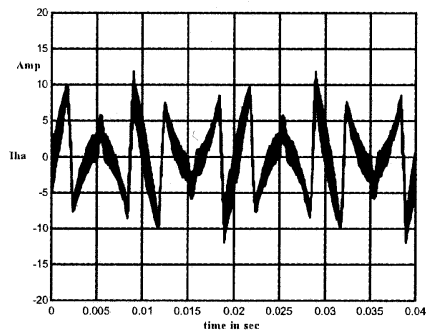

(c)

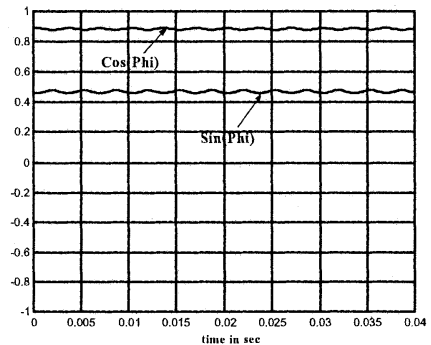

(e)

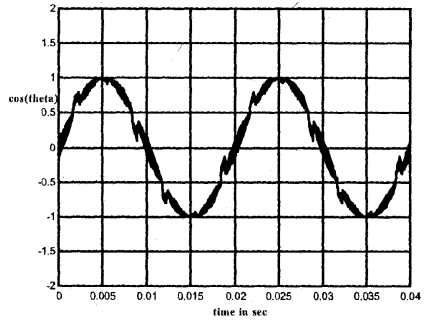

(g)

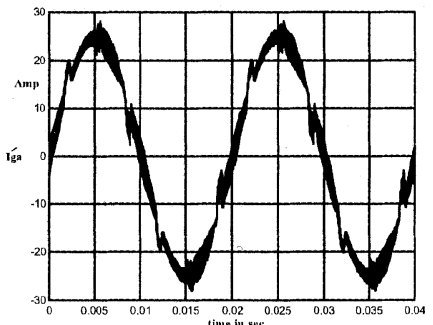

(b)

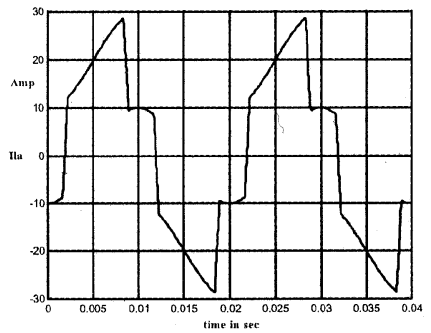

(d)

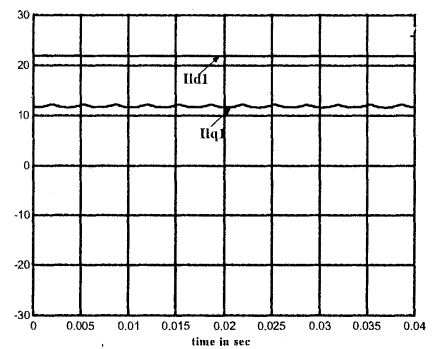

(f)

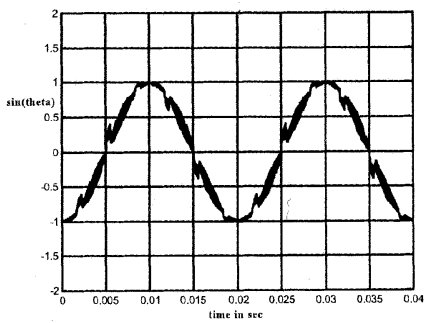

(h)
Fig. 6. Simulation results of the PAB controller with load consisting of 20-A (peak) diode rectifier and 10-A (peak) reactive lag. (a) Input phase current $i_{g a}$. (b) $i_{g a}^{\prime}$. (c) Filter current $i_{h a}$. (d) Load current $i_{l a}$. (e) $\sin \left(\varphi_{s}\right)$. (f) $i_{l 1_{-} p d}, i_{l 1_{-} p q}$. (g) $\cos (\theta)(h) \sin (\theta)$.

The angular frequency of the fundamental component is $\omega_{f}$. Therefore, the square of the magnitude of $\left(\overline{i_{l}}\right)$ can be written as

$$
\left|\overline{i_{l}}\right|^{2}=i_{l a}^{2}+i_{l \beta}^{2}=\sum_{k=1}^{\infty}\left(I_{l k_{-} p}^{2}+I_{l k_{-} n}^{2}\right)+f_{p}
$$

All the frequency-dependent terms are combined together as $f_{p}$. We can eliminate the high-frequency components of $\left|\overline{i_{l}}\right|^{2}$ by passing it through a low-pass filter (LPF), then take a square root of the output of the filter to get $\left|\overline{i_{l}}\right|_{\text {fil }}$

$$
\left|\bar{i}_{l}\right|_{\text {fil }}=\sqrt{\sum_{k=1}^{\infty}\left(I_{l k \_p}^{2}+I_{l k \_n}^{2}\right)} .
$$

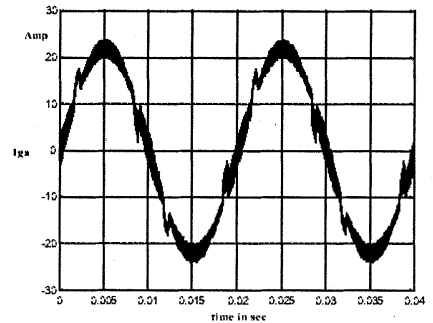

(a)

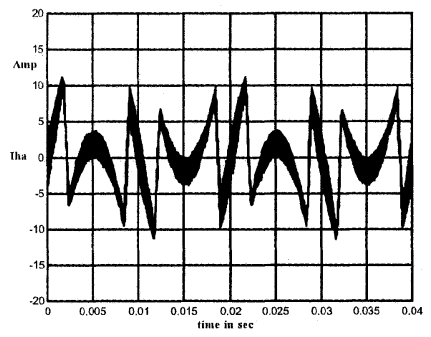

(c)

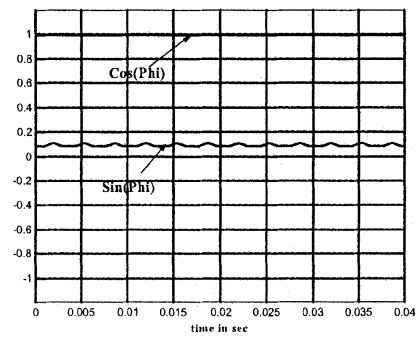

(e)

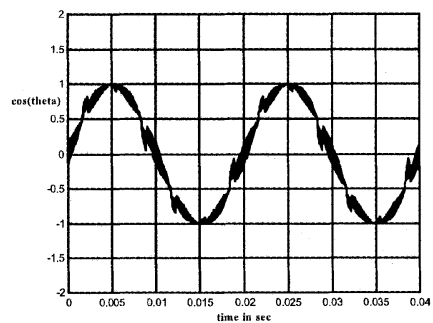

(g)

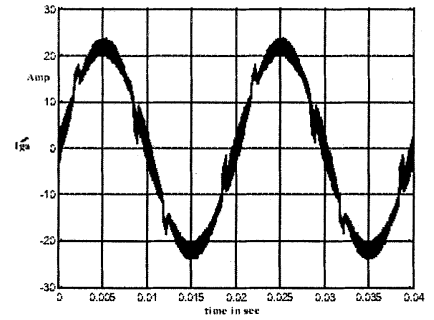

(b)

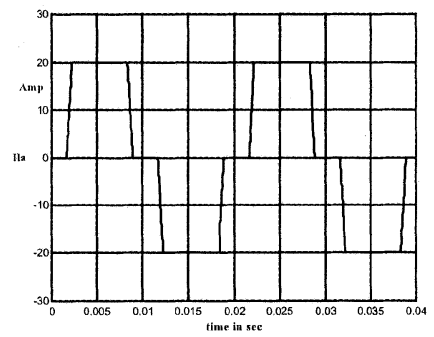

(d)

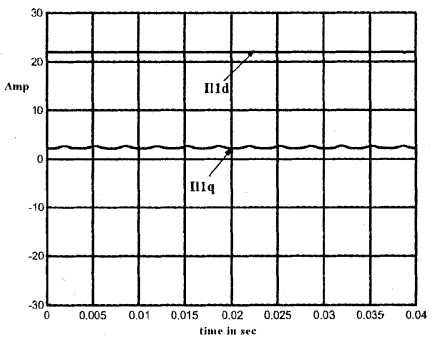

(f)

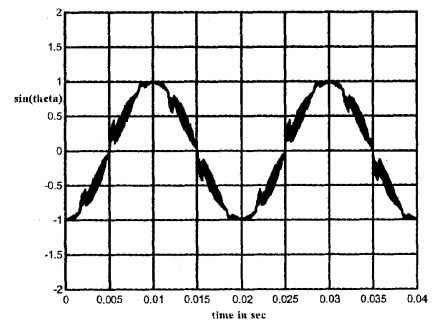

(h)
Fig. 7. Simulation results of the PAB controller with 20-A (peak) diode rectifier load. (a) Input phase current $i_{g a}$. (b) $i_{g a}^{\prime}$. (c) Filter current $i_{h a}$. (d) Load current $i_{l a}$. (e) $\sin \left(\varphi_{s}\right)$. (f) $i_{l 1 \_p d}, i_{l 1 \_p q} \cdot(\mathrm{g}) \cos (\theta) .(h) \sin (\theta)$.

The magnitude of the input current is made equal to the $\left|\overline{i_{l}}\right|_{\text {fil }}$ by the outer loop proportional plus integral (PI) controller. Therefore, the PI controller ensures that

$$
I_{g 1}=\left|\overline{i_{l}}\right|_{\mathrm{fil}}=\sqrt{\sum_{k=1}^{\infty}\left(I_{l k_{\_} p}^{2}+I_{l k_{-} n}^{2}\right)} .
$$

The output of the PI controller gives us the magnitude of $\sin \left(\varphi_{s}\right)$, or $\left|\sin \left(\varphi_{s}\right)\right|$. By monitoring $i_{g \beta}^{\prime}$ and $i_{l \beta}$ we can determine whether the load current is leading or lagging the input voltage. This information is binary in nature because it has only two values: $m=+1$ for lagging current and $m=-1$ for leading current

$$
\sin \left(\varphi_{s}\right)=m\left|\sin \left(\varphi_{s}\right)\right|
$$




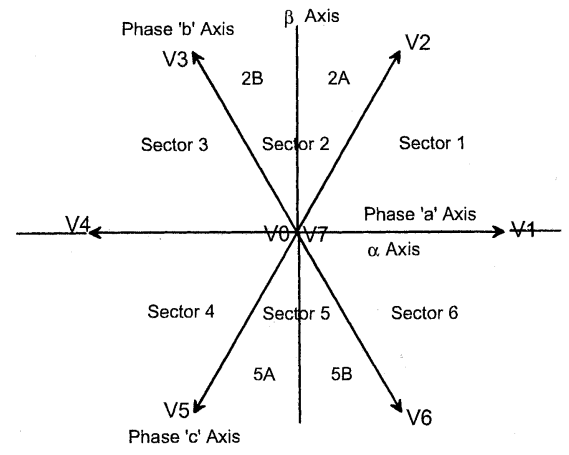

Fig. 8. Voltage vectors produced by the converter and the definitions of the corresponding sectors.

TABLE I

GENERATION OF RECTIFIED CURRENT VARIABLES

\begin{tabular}{c|c|r}
\hline Sector & $i_{g r a}^{\prime}[n]$ & $i_{g r \beta}^{\prime}[n]$ \\
\hline 1 & $i_{g a}^{\prime}[n]$ & $i_{g \beta}^{\prime}[n]$ \\
\hline $2 A$ & $i_{g a}^{\prime}[n]$ & $i_{g \beta}^{\prime}[n]$ \\
\hline $2 B$ & $-i_{g a}^{\prime}[n]$ & $i_{g \beta}^{\prime}[n]$ \\
\hline 3 & $-i_{g a}^{\prime}[n]$ & $i_{g \beta}^{\prime}[n]$ \\
\hline 4 & $-i_{g a}^{\prime}[n]$ & $-i_{g \beta}^{\prime}[n]$ \\
\hline $5 A$ & $-i_{g a}^{\prime}[n]$ & $-i_{g \beta}^{\prime}[n]$ \\
\hline $5 B$ & $i_{g a}^{\prime}[n]$ & $-i_{g \beta}^{\prime}[n]$ \\
\hline 6 & $i_{g a}^{\prime}[n]$ & $-i_{g \beta}^{\prime}[n]$ \\
\hline
\end{tabular}

$$
\cos \left(\varphi_{s}\right)=\sqrt{1-\sin ^{2}\left(\varphi_{s}\right)}
$$

This method of calculation of phase shift $\varphi_{s}$ is computationally simple but not very exact. The reason for that is given below. From the power balance condition on the input source and the nonlinear load we get

$$
I_{g 1} \cos \left(\varphi_{s}\right)=I_{l 1_{-} p} \cos \left(\varphi_{1 \_p}\right)
$$

where $\varphi_{1_{-} p}$ is the phase angle of the fundamental frequency positive-sequence component of the load current.

Therefore,

$$
\begin{aligned}
\varphi_{s} & =\cos ^{-1}\left(\frac{I_{l 1_{\_} p}}{\sqrt{\sum_{k=1}^{\infty}\left(I_{l k_{-} p}^{2}+I_{l k \_n}^{2}\right)}} \cos \left(\varphi_{1_{1} p}\right)\right) \\
& =\cos ^{-1}\left(K_{\varphi} \cos \left(\varphi_{1_{-} p}\right)\right) .
\end{aligned}
$$

$K_{\varphi}$ can be expressed as

$$
K_{\varphi}=\frac{1}{\sqrt{1+T_{D}^{2}}}
$$

where the total distortion coefficient $T_{D}$ is defined as

$$
T_{D}=\sqrt{\frac{I_{l 1 \_n}^{2}+\sum_{k=2}^{\infty}\left(I_{l k_{-} p}^{2}+I_{l k_{-} n}^{2}\right)}{I_{l 1 \_p}^{2}}} .
$$

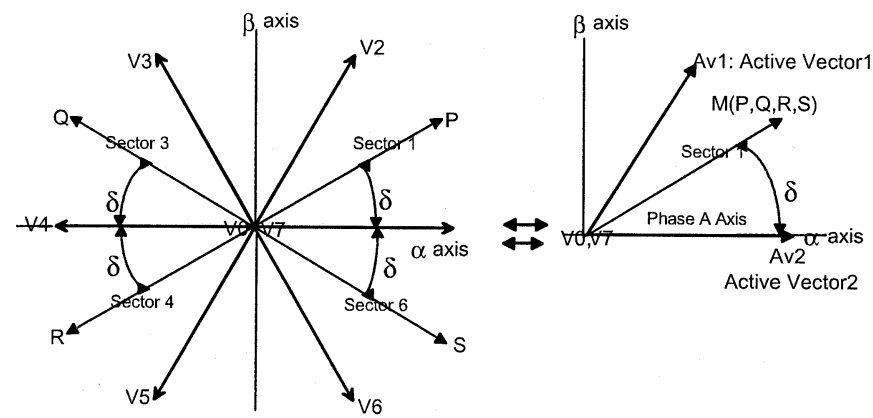

Fig. 9. Mapping of $\mathrm{P}, \mathrm{Q}, \mathrm{R}$, and $\mathrm{S}$ vectors into $\mathrm{M}$ of Sector 1 of positive $a, \beta$ axis for solution of $T_{1}, T_{2}$.

TABLE II

Selection of Active Vectors IN Sectors 1, 3, 4, AND 6

\begin{tabular}{c|r|r}
\hline Sector & $A_{v 1}$ & $A_{v 2}$ \\
\hline 1 & $V 2$ & $V 1$ \\
\hline 3 & $V 3$ & $V 4$ \\
\hline 4 & $V 5$ & $V 4$ \\
\hline 6 & $V 6$ & $V 1$ \\
\hline
\end{tabular}

Ideally, we would like the controller to make the input current phase shifted by an amount equal to the phase angle of the line-frequency positive-sequence component of the load current, that is, we want $\varphi_{s}=\varphi_{1_{-} p}$. Under that condition, the SAF will compensate only for the harmonics and both the active and reactive components of the load current will be supplied from the input. However, it can be seen from (14) that this principle is not exactly followed in this implementation. Instead, some phase-angle error gets introduced that depends on the total distortion coefficient $T_{D}$ of the load current. This would mean that the input current though free from harmonics will not supply power at the optimum power factor. However, in most cases this error in magnitude of the input current is not significant. For example, if $T_{D}$ is $28 \%$, as would be in the case of a diode bridge rectifier, then the magnitude of the input current will be $3.8 \%$ more than what is possible to achieve through perfect compensation.

If we approximate $\sqrt{\sum_{k-1}^{\infty}\left(I_{l k_{-} p}^{2}+I_{l k_{-} n}^{2}\right)}$ as $I_{l 1_{-} p}$, then

$$
\begin{aligned}
I_{g 1} & =I_{l 1_{1} p} \\
\varphi_{s} & =\varphi_{1_{1} p} .
\end{aligned}
$$

Method II: It is possible to implement perfect compensation for harmonics with some extra computational requirements on the controller. The fundamental-frequency positive-sequence current $\overline{I_{l 1_{-} p}}$ can be extracted from the load current in the synchronously rotating $\left(d_{1-p}, q_{1-p}\right)$ reference frame. For that, it is not even necessary to sense the input voltage $\overline{\nu_{g}}$ as would be required in other methods.

This is due to the reason that the internal control variable $\overline{i_{g}^{\prime}}$ is proportional to $\overline{\nu_{g}}$. Therefore, as shown in Fig. 5(c),

$$
\cos (\theta)=\frac{i_{g a}^{\prime}}{\sqrt{\left(i_{g a}^{\prime}\right)^{2}+\left(i_{g \beta}^{\prime}\right)^{2}}}
$$




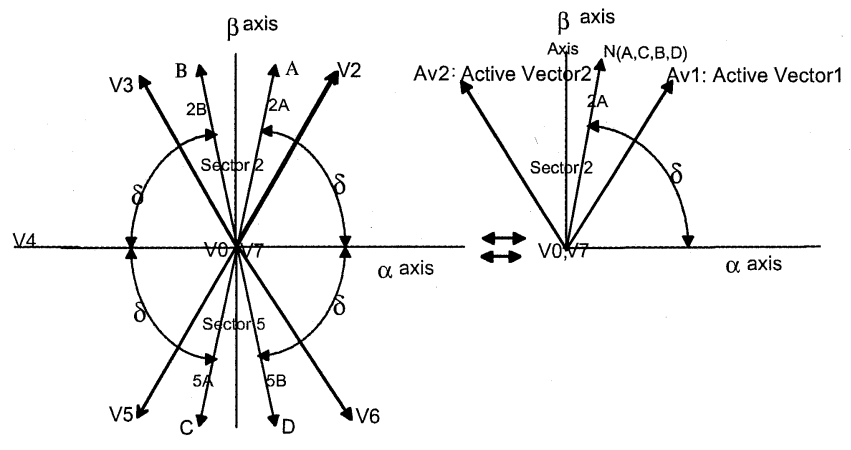

Fig. 10. Mapping of A, B, C, and D vectors into $\mathrm{N}$ of Sector 2 of positive $a$, $\beta$ axis for solution of $T_{1}, T_{2}$.

TABLE III

SELECTION OF ACtive Vectors IN Sectors 2A, 2B, 5A, AND 5B

\begin{tabular}{r|r|r}
\hline Sector & $A_{v 1}$ & $A_{v 2}$ \\
\hline $2 A$ & $V 2$ & $V 3$ \\
\hline $2 B$ & $V 3$ & $V 2$ \\
\hline $5 A$ & $V 5$ & $V 6$ \\
\hline $5 B$ & $V 6$ & $V 5$ \\
\hline
\end{tabular}

$$
\sin (\theta)=\frac{i_{g \beta}^{\prime}}{\sqrt{\left(i_{g a}^{\prime}\right)^{2}+\left(i_{g \beta}^{\prime}\right)^{2}}}
$$

Therefore,

$$
\begin{aligned}
i_{l_{-} p d} & =i_{l a} \cos (\theta)+i_{l \beta} \sin (\theta) \\
-i_{l_{-} p q} & =-i_{l a} \sin (\theta)+i_{l \beta} \cos (\theta) .
\end{aligned}
$$

Subsequently, we pass $i_{l_{-} p d}$ and $i_{l_{-} p q}$ through LPFs to eliminate the ac content in the waveform and get the dc quantities $\left(i_{l 1 \_p d}, i_{l 1 \_p q}\right)$ corresponding to the fundamental-frequency positive-sequence component of the load current $\overline{i_{l 1} p}$. From $\left(i_{l 1_{-} p d}, i_{l 1_{-} p q}\right)$ the $\sin \left(\varphi_{s}\right)$ and $\cos \left(\varphi_{s}\right)$ can be computed as

$$
\begin{aligned}
\cos \left(\phi_{s}\right) & =\frac{i_{l 1_{-} p d}}{\sqrt{\left(i_{l 1 \_p d}\right)^{2}+\left(i_{l 1 \_p q}\right)^{2}}} \\
\sin \left(\phi_{s}\right) & =\frac{i_{l 1 \_p q}}{\sqrt{\left(i_{l 1 \_p d}\right)^{2}+\left(i_{l 1 \_p q}\right)^{2}}} .
\end{aligned}
$$

Alternatively, the magnitude $i_{l 1_{-} p}$ of can be obtained from (25) and the phase angle of the input current, $\varphi_{s}$, can be determined by the closed-loop PI controller, as in Method I

$$
\left|\overline{i_{l 1_{-} p}}\right|=\sqrt{i_{l 1_{-} p d}^{2}+i_{l 1_{-} p q}^{2}} \text {. }
$$

\section{Simulation Results}

The SAF with the proposed PAB controller is simulated in the MATLAB-SIMULINK (version 5.3) simulation environment. The nonlinear load is of $20 \mathrm{~A}$ peak, as shown in Fig. 7(d). The shape of the current and its rise and fall times are so chosen that it approximately models a three-phase diode bridge rectifier. The per phase inductance of the shunt active filter is 0.75 $\mathrm{mH}$. The output dc voltage of SAF is regulated by an outer loop

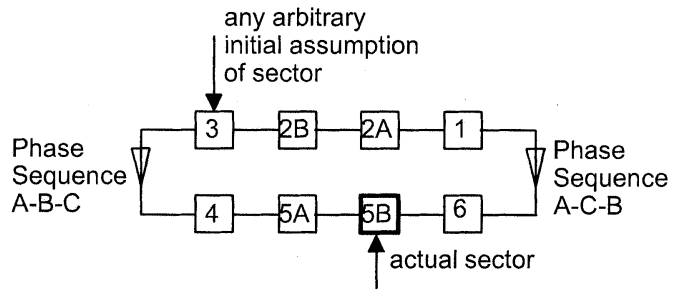

Fig. 11. Sequence of sector change to be followed to eventually synchronize with the input voltage vector. For example, if for the present switching period the actual voltage vector is in sector $5 \mathrm{~B}$ but the initial assumption of sector is 3 , then sectors 3,4 , and $5 \mathrm{~A}$ will not produce an acceptable solution but the modulator will lock at sector $5 \mathrm{~B}$

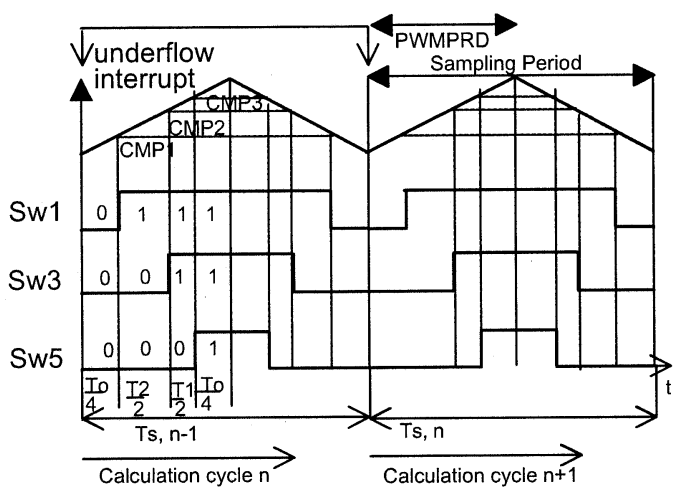

Fig. 12. Generation of symmetrical PWM signals Sw1, Sw3 and Sw5 using the Full Compare Unit of the TMS320F240 DSP in sector 1 of the input voltage vector.

PI regulator. The switching frequency of the converter is chosen to be $10 \mathrm{kHz}$. It is desirable that the switching frequency of the SAF is made as high as possible. At higher switching frequency the filter inductance can be made lower and better dynamics can be extracted by the current controller. However, in this case the choice is dictated by the limitations of the general purpose TMS320F240 digital controller that has been used for the hardware implementation of the control algorithm $(20-\mathrm{MHz}$ CPU, 6.6- $\mu$ s ADC). The simulation results for two types of load with method II of the PAB control are presented in Figs. 6 and 7. Method I provides practically the same results, therefore, it is not reported separately. In simulation, two cases are considered. In case I, the load is diode-rectifier-type nonlinear along with line-frequency reactive current of $10 \mathrm{~A}$ peak. The simulated waveforms are shown in Fig. 6. In case II, the load has no linefrequency reactive component but consists only of 20-A peak nonlinear current. The simulated waveforms are shown in Fig. 7.

\section{DIGITAL IMPLEMENTATION}

This section describes the digital implementation procedure of the PAB controller. We sense two phase currents $\left(i_{h a}, i_{h b}\right)$ of the harmonic filter (instead of $\left(i_{h a}, i_{h b}\right)$ the input currents $\left(i_{g a}\right.$, $i_{g b}$ ) can also be sensed). Two phase currents of the nonlinear load $\left(i_{l a}, i_{l b}\right)$ should also be sensed. The output dc voltage of the shunt harmonic filter is sensed and regulated at the reference value. The $a$ - and $\beta$-axes components of the sensed currents for the " $n$ th" switching period are given by (26)-(29)

$$
i_{h a}[n]=i_{h a}[n]
$$


TABLE IV

GENERATION OF SyMMETRICAL PWM PULSES USING TMS320F240

\begin{tabular}{c|l|l|l}
\hline Sector & \multicolumn{1}{|c|}{$C M P 1$} & \multicolumn{1}{c}{$C M P 2$} & \multicolumn{1}{c}{$C M P 3$} \\
\hline 1 & $T_{x}=\left(T_{s}-T_{1}-T_{2}\right) / 4$ & $T_{x}+T_{2} / 2$ & $T_{x}+T_{2} / 2+T_{1} / 2$ \\
\hline $2 A$ & $T_{x}+T_{2} / 2$ & $T_{x}=\left(T_{s}-T_{1}-T_{2}\right) / 4$ & $T_{x}+T_{2} / 2+T_{1} / 2$ \\
\hline $2 B$ & $T_{x}+T_{1} / 2$ & $T_{x}=\left(T_{s}-T_{1}-T_{2}\right) / 4$ & $T_{x}+T_{2} / 2+T_{1} / 2$ \\
\hline 3 & $T_{x}+T_{2} / 2+T_{1} / 2$ & $T_{x}=\left(T_{s}-T_{1}-T_{2}\right) / 4$ & $T_{x}+T_{1} / 2$ \\
\hline 4 & $T_{x}+T_{2} / 2+T_{1} / 2$ & $T_{x}+T_{1} / 2$ & $T_{x}=\left(T_{s}-T_{1}-T_{2}\right) / 4$ \\
\hline $5 A$ & $T_{x}+T_{1} / 2$ & $T_{x}+T_{2} / 2+T_{1} / 2$ & $T_{x}=\left(T_{s}-T_{1}-T_{2}\right) / 4$ \\
\hline $5 B$ & $T_{x}+T_{2} / 2$ & $T_{x}+T_{2} / 2+T_{1} / 2$ & $T_{x}=\left(T_{s}-T_{1}-T_{2}\right) / 4$ \\
\hline 6 & $T_{x}=\left(T_{s}-T_{1}-T_{2}\right) / 4$ & $T_{x}+T_{2} / 2+T_{1} / 2$ & $T_{x}+T_{2} / 2$ \\
\hline
\end{tabular}

$$
\begin{aligned}
i_{h \beta}[n] & =\frac{1}{\sqrt{3}}\left(2 i_{h b}[n]+i_{h a}[n]\right) \\
i_{l a}[n] & =i_{l a}[n] \\
i_{l \beta}[n] & =\frac{1}{\sqrt{3}}\left(2 i_{l b}[n]+i_{l a}[n]\right) .
\end{aligned}
$$

The $a$ - and $\beta$-axes components of the input current can be calculated as

$$
\begin{aligned}
& i_{g a}[n]=i_{h a}[n]+i_{l a}[n] \\
& i_{g \beta}[n]=i_{h \beta}[n]+i_{l \beta}[n] .
\end{aligned}
$$

Let us assume that $\sin \left(\varphi_{s}\right)$ and $\cos \left(\varphi_{s}\right)$ are known to the controller at this point, then $i_{g a}^{\prime}[n]$ and $i_{g \beta}^{\prime}[n]$ can be obtained from (32) and (33)

$$
\begin{aligned}
i_{g a}^{\prime}[n] & =i_{g a}[n] \cos \varphi_{s}-i_{g \beta}[n] \sin \varphi_{s} \\
i_{g \beta}^{\prime}[n] & =i_{g a}[n] \sin \varphi_{s}+i_{g \beta}[n] \cos \varphi_{s} .
\end{aligned}
$$

The voltage vectors produced by the switching of a three-phase two-level pulsewidth-modulation (PWM) converter are shown in Fig. 8. The corresponding switching sectors are also defined in the same figure. From the sector change logic (described in a later part of this section) the sector of the input voltage vector is known to the controller. Using the sector information the rectified current variables $i_{g r a}^{\prime}[n]$ and $i_{g r \beta}^{\prime}[n]$ are obtained from Table I. The continuous-conduction mode input-output conversion equations of the boost converter are

$$
\begin{aligned}
v_{g a} & =\left(1-d_{a}\right) V_{o} \\
v_{g \beta} & =\left(1-d_{\beta}\right) V_{o} .
\end{aligned}
$$

Therefore, under closed-loop operation the duty ratios can be calculated from

$$
\begin{aligned}
& d_{a}[n]=1-\frac{i_{g r a}^{\prime}[n]}{I_{m}} \\
& d_{\beta}[n]=1-\frac{i_{g r \beta}^{\prime}[n]}{I_{m}} .
\end{aligned}
$$

$I_{m}=V_{o} / R_{e}$ is the output of the outer loop PI controller that regulates the output dc voltage $V_{o}$ of the SAF. $d_{a} \geq 0$ and $d_{\beta} \geq 0$ are the corresponding duty ratios of $a$ - and $\beta$-axes converters. In implementation, we need to satisfy (36) and (37) simultaneously in every switching period of the converter by applying the voltage vectors shown in Fig. 8. From $d_{a}[n]$ and $d_{\beta}[n]$, we can calculate the time duration $T_{1}[n]$ and $T_{2}[n]$ for the two active vectors $A_{\nu 1}$ and $A_{\nu 2}$, respectively, by using the principle of volt-second balance. The remaining time $T_{0}[n]$ of the switching period $T_{s}$ should be used by the null vector $A_{\nu 0}$. From Fig. 9, it can be noted that if the active vectors $A_{\nu 1}$ and $A_{\nu 2}$ for sectors $1,3,4$, and 6 are identified as in Table II, then the corresponding duty ratio $d_{1}[n]=\left(T_{1}[n]\right) / T_{s}$ and $d_{2}[n]=$ $\left(T_{2}[n]\right) / T_{s}$, needed for synthesis of any vector $(P, Q, R$ or $S)$ that makes an angle $\delta$ with respect to the $a$ axis of the segment, can be obtained as

$$
\begin{aligned}
& d_{1}[n]=\frac{2}{\sqrt{3}}\left(1-d_{\beta}[n]\right) \\
& d_{2}[n]=\left(1-d_{a}[n]\right)-\left(\frac{1}{2}\right) \cdot d_{1}[n] .
\end{aligned}
$$

Similarly, for sectors 2A, 2B, 5A, and 5B, as shown in Fig. 10, Table III gives the selection of vectors. The $d_{1}[n]$ and $d_{2}[n]$ can be calculated from (40) and (41)

$$
\begin{aligned}
& d_{1}[n]=\left(1-d_{a}[n]\right)+\frac{1}{\sqrt{3}}\left(1-d_{\beta}[n]\right) \\
& d_{2}[n]=d_{1}[n]-2\left(1-d_{a}[n]\right) .
\end{aligned}
$$

The duty ratio of the null vector is given by

$$
d_{0}[n]=1-d_{1}[n]-d_{2}[n]
$$

The controller implements self-synchronization of the converter switching with respect to input voltage based on the 


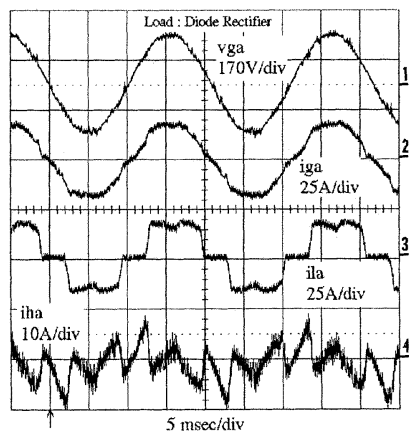

(a)

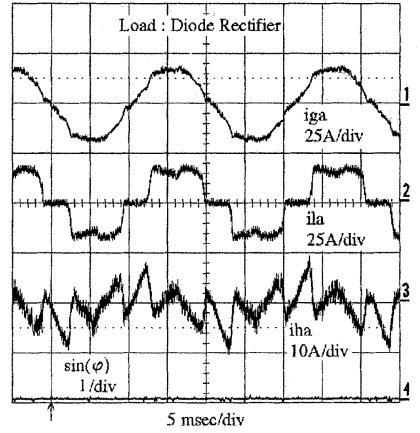

(c)

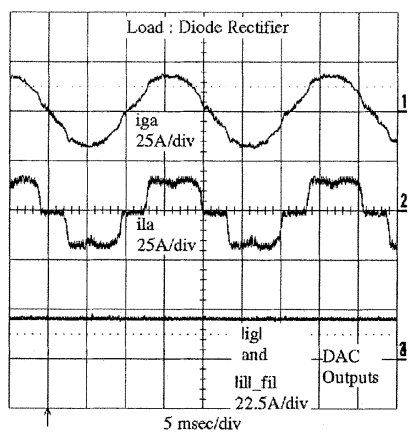

(e)

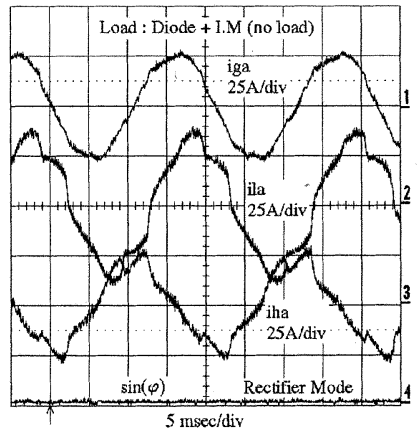

(g)

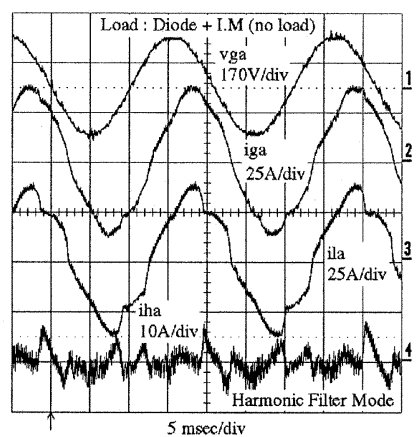

(b)

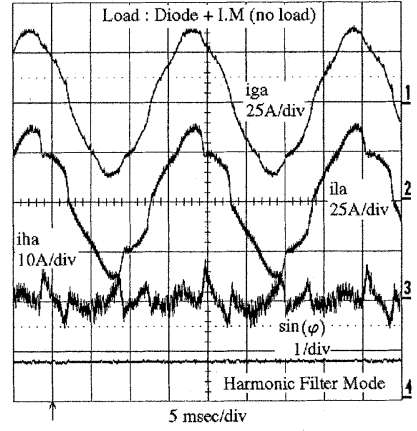

(d)

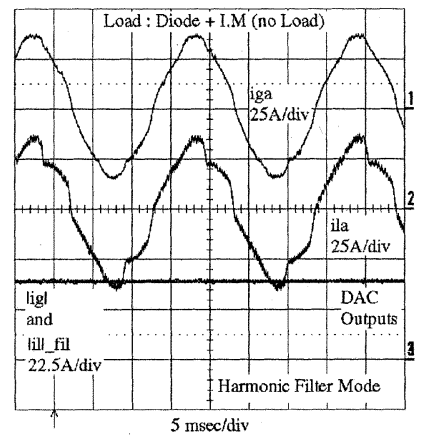

(f)

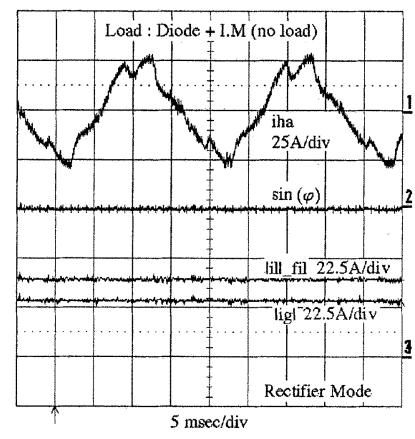

(h)

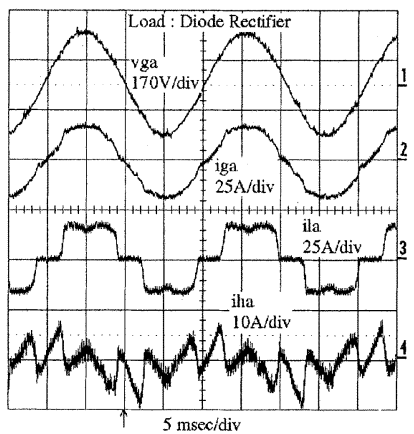

(a)

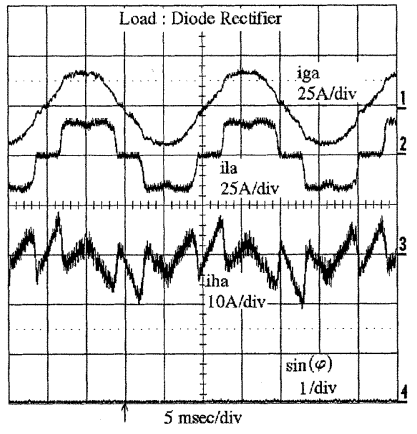

(c)

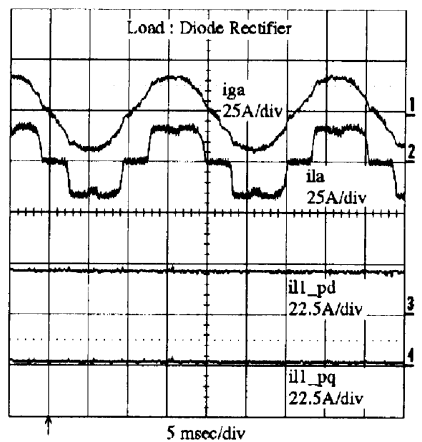

(e)

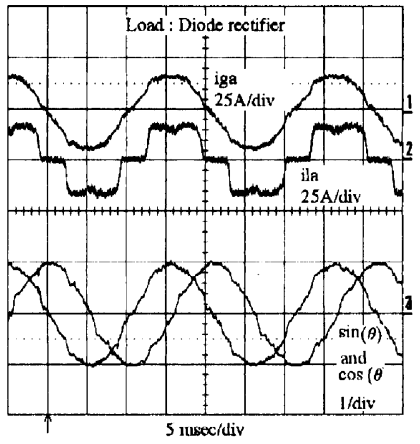

(g)

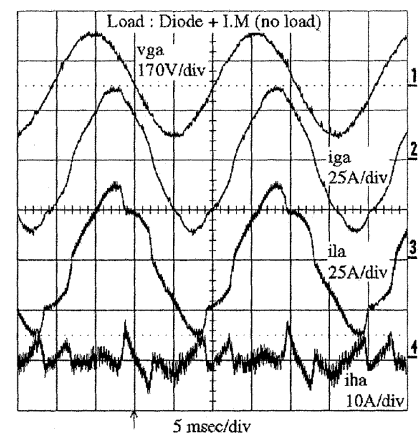

(b)

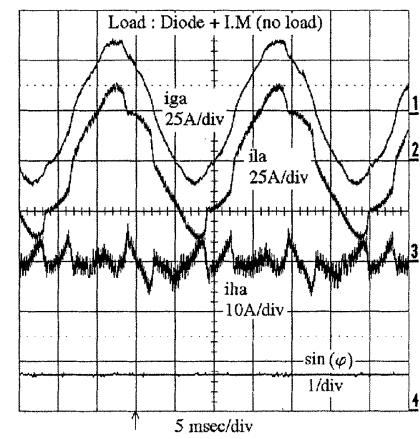

(d)

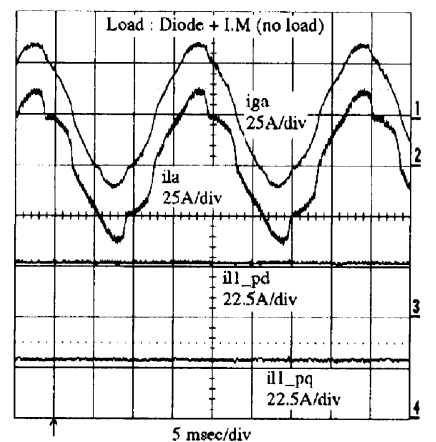

(f)

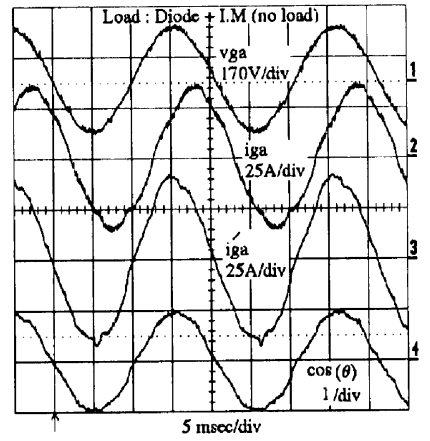

(h)

Fig. 13. Experimental results of the PAB Control Method I. (a) Diode- $\left(\nu_{g a}\right)$, $\left(i_{g a}\right),\left(i_{l a}\right),\left(i_{h a}\right)$. (b) Diode plus IM (no load)- $\left(\nu_{g a}\right),\left(i_{g a}\right),\left(i_{l a}\right),\left(i_{h a}\right)$. (c) Diode- $\left(i_{g a}\right),\left(i_{l a}\right),\left(i_{h a}\right), \sin \left(\varphi_{s}\right)$. (d) Diode plus IM (no load)- $\left(i_{g a}\right)$, $\left(i_{l a}\right),\left(i_{h a}\right), \sin \left(\varphi_{s}\right)$. (e) Diode- $\left(i_{g a}\right),\left(i_{l a}\right),\left|\overline{i_{g}}\right|,\left|\overline{i_{l}}\right|_{\text {fil }}$. (f) Diode plus IM (no load)-(iga $),\left(i_{l a}\right),\left|\overline{i_{g}}\right|,\left|\overline{i_{l}}\right|_{\text {fil }}$. (g), (h) Diode plus IM (no load)-high-power-factor mode- $(g)\left(i_{g a}\right),\left(i_{l a}\right),\left(i_{h a}\right), \sin \left(\varphi_{s}\right)(h)\left(i_{h a}\right)$, $\sin \left(\varphi_{s}\right),\left|\overline{i_{l}} \overline{f i l}_{\text {il }}\right|,\left|\overline{i_{g}}\right|$.

following logic: as long as the sector selection is correct, the $a$ - and $\beta$-axes modulators will produce duty ratios less than 1 , i.e., $d_{a}[n]<1, d_{\beta}[n]<1$. Further, $d_{2}[n]>0$ has also to be true

Fig. 14. Experimental results of the PAB Control Method II. (a) Diode- $\left(\nu_{g a}\right),\left(i_{g a}\right),\left(i_{l a}\right),\left(i_{h a}\right)$. (b) Diode plus IM (no load)- $\left(\nu_{g a}\right),\left(i_{g a}\right)$, $\left(i_{l a}\right),\left(i_{h a}\right)$. (c) Diode- $\left(i_{g a}\right),\left(i_{l a}\right),\left(i_{h a}\right), \sin \left(\varphi_{s}\right)$. (d) Diode plus IM (no load)— $\left(i_{g a}\right),\left(i_{l a}\right),\left(i_{h a}\right), \sin \left(\varphi_{s}\right)$. (e) Diode- $\left(i_{g a}\right),\left(i_{l a}\right), i_{l 1-p d}, i_{l 1-p q}$. (f) Diode plus IM (no load)- $\left(i_{g a}\right),\left(i_{l a}\right), i_{l 1 \_p d}, i_{l 1}-p q$. (g) Diode- $\left(i_{g a}\right)$, $\left(i_{l a}\right), \cos (\theta), \sin (\theta)$. (h) Diode plus IM (no load)—( $\left.i_{g a}\right),\left(i_{l a}\right), i_{g a}^{\prime}, \cos (\theta)$.

for the modulator to produce valid switching pulses for the SAF converter. When any one of these conditions are not satisfied, the next sector in sequence is chosen, as shown in Fig. 11. 


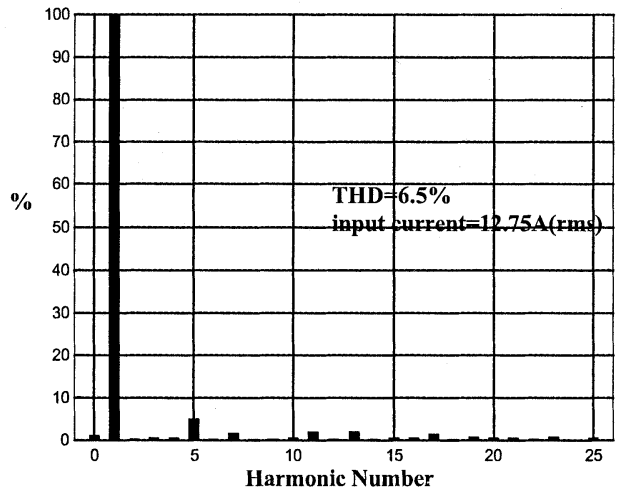

(a)

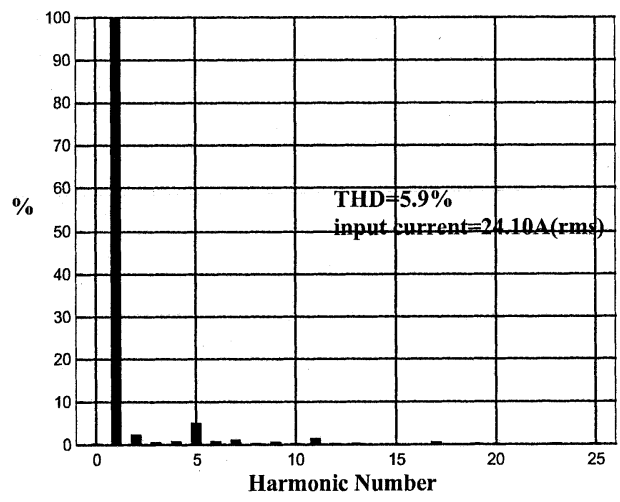

(c)

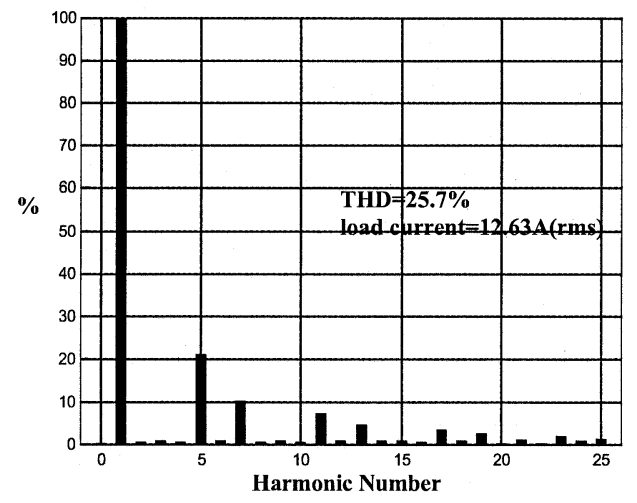

(b)

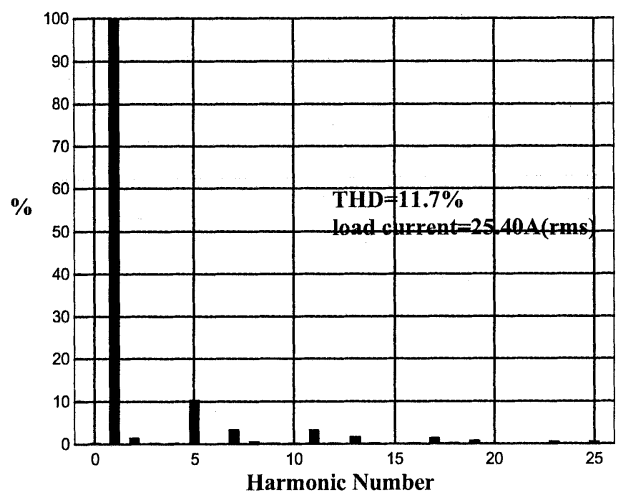

(d)

Fig. 15. Harmonic spectrum of (a) input current with diode load $i_{g a}$, (b) diode rectifier load current $i_{l a}$, (c) input current under diode plus IM load $i_{g a}$, and (d) load diode plus IM (no load) current $i_{l a}$.

It may be noted that the duty ratio control law is input voltage sensorless and can be expressed with a few simple formulas. Therefore, it can be said that the computational overhead of this input voltage sensorless algorithm is not substantial.

It has been assumed in the above algorithm that $\varphi_{s}$ is known to the controller. In method I of the PAB controller $\sin \left(\varphi_{s}\right)$ and $\cos \left(\varphi_{s}\right)$ are determined in closed loop. First, $\left|\overline{i_{l}}\right|^{2}$ (load current magnitude square) is computed from (43)

$$
\left|\overline{i_{l}}\right|^{2}=i_{l a}^{2}+i_{l \beta}^{2}
$$

This quantity is then filtered by an LPF and square root is taken on the filtered output to get $\left|\bar{i}_{l}\right|_{\text {fil }}$. The magnitude of the input current phasor is computed as

$$
\left|\overline{i_{g}}\right|=\sqrt{i_{g a}^{2}+i_{g \beta}^{2}} .
$$

The difference in the magnitudes of these two quantities, that is, $\left|\overline{i_{l}}\right|_{\text {fil }}-\left|\overline{i_{g}}\right|$, is treated as an input signal to the PI controller. The output of the PI controller is the magnitude of $\sin \left(\varphi_{s}\right)$. It passes through a limit check where maximum value is set as one and the minimum value as zero. The information whether the load power factor is leading or lagging, or the value of $m$ in (11), is binary in nature. It can be obtained even without sensing the input voltage by processing $i_{g \beta}^{\prime}$ and $i_{l \beta}$. This is because $i_{g \beta}^{\prime}$ is proportional to input voltage $\nu_{g \beta}$. Then, the values of $\sin \left(\varphi_{s}\right)$ and $\cos \left(\varphi_{s}\right)$ are calculated from (11) and (12).
In method II of the implementation (19)-(24) are used to compute $\sin \left(\varphi_{s}\right)$ and $\cos \left(\varphi_{s}\right)$, as described in Section II.

The control algorithm is implemented in a Texas Instruments DSP TMS320F240F. It has three 16-bit registers [8], namely, CMP1, CMP2, and CMP3, to control the individual duty cycles of the switches as shown in Fig. 12. The values that are to be loaded on to these registers to generate symmetrical PWM pulses are given in Table IV.

\section{EXPERIMENTAL VERIFICATION}

The general-propose DSP TMS320F240 has been used to implement the (PAB) control in digital hardware. It has a CPU clock frequency of $20 \mathrm{MHz}$ and the ADC conversion time is 6.6 $\mu \mathrm{s}$. The execution time of the PAB algorithm is approximately $50 \mu \mathrm{s}$ in the TMS320F240. The power hardware of the prototype PWM converter is built on an intelligent power module (IPM) switched at $10 \mathrm{kHz}$ that corresponds to the control loop time of $T_{s}=100 \mu$ s (underflow interrupt of Fig. 12). The per phase filter inductance is $0.75 \mathrm{mH}$. The filter and load currents are measured but input voltages are not sensed. The output of the shunt harmonic filter is regulated at $375 \mathrm{~V}$. A nonlinear load of 12.7 A(rms) rating is constructed by using a three-phase diode bridge rectifier connected to the resistive load. A predominantly reactive load of $24.7 \mathrm{~A}(\mathrm{rms})$ is constructed by adding an induction motor (IM) under no load to the already available nonlinear load of the diode bridge rectifier in order to verify that the phase shift control algorithm compensates only for the harmonics but 
not for the reactive current of the load. However, if we deliberately set $\sin \varphi_{s}=0$ and $\cos \varphi_{s}=1$, then the SAF can be used for compensation of both reactive and harmonic currents and the entire SAF system works like a high-power-factor boost rectifier. The experimental waveforms are shown in Figs. 13 and 14. In particular, Fig. 13(g) and Fig. 13(h) demonstrate the operation of the SAF as a PFC rectifier.

The total harmonic distortion (THD) of the rectifier current is $25.7 \%$ and the THD of the input current with the PAB control is $6.5 \%$. The frequency spectrum of the input and load currents are measured using LEM HEME ANALYST 2060 and are shown in Fig. 15. The input voltage of the experimental converter is not an ideal sine wave but itself has a THD of $1.8 \%$. It has been found that there is no substantial difference in the input current THD results between the two methods of PAB control that are proposed in this paper. It may be noted that the harmonic performance can be further improved by using a lower value of per-phase inductance in SAF. However, in that case, the switching frequency of the converter should be increased. This in effect means that a DSP with faster CPU speed and lower ADC conversion time than the TMS 320F240 should be used. This is due to the reason that, at a higher switching frequency, the ADC conversion time of TMS320F240 is substantial compared to the loop time of the control algorithm.

\section{CONCLUSION}

In this paper, the PAB control for filtering the harmonic components of the nonlinear load is proposed for an SAF. The harmonic filtering objective is defined as the task of balancing the phase angle of the input current with the phase angle of the line-frequency component of the load current. To achieve this objective the input current is sensed, phase shifted by a specific amount and then made proportional to the input voltage. Two methods are described in this paper for determination of the required phase shift. The current-mode control algorithm is input voltage sensorless, without PLL and suitable for digital implementation with currents being sampled only once in a switching period. The PAB control has the flexibility to compensate only for the harmonics of the load current so that the current rating requirement of the converter can be made lower than the converter with both reactive and harmonics compensation. However, if required, this method can compensate for the reactive component of the load current as well and thereby shape the input current like input voltage. In conclusion, it can be said that the PAB control is a simple but effective harmonic filtering technique for loads that support unidirectional power flow from input to load.

\section{REFERENCES}

[1] S. Chattopadhyay and V. Ramanarayanan, "Digital implementation of a line current shaping algorithm for three phase high power factor Boost rectifier without input voltage sensing," in Proc. IEEE APEC'01, 2001, pp. 592-600.

[2] H. Akagi, Y. Kanazawa, and A. Nabae, "Instantaneous reactive power compensators comprising switching devices without energy storage components," IEEE Trans. Ind. Applicat., vol. IA-20, pp. 625-630, May/June 1984.

[3] S. Bhattacharya, D. M. Divan, and B. Banerjee, "Synchronous reference harmonic isolator using active series filter," in Proc. EPE Conf., Florence, Italy, 1991, pp. 30-35.

[4] V. Soares, P. Verdelho, and G. D. Marques, "An instantaneous active and reactive current component method for active filters," IEEE Trans. Power Electron., vol. 15, pp. 660-669, July 2000.

[5] K. M. Smedley, L. Zhou, and C. Qjao, "Unified constant -frequency integration control of active power filters -steady state and dynamics," IEEE Trans. Power Electron., vol. 16, pp. 428-436, May 2001.

[6] M. Malinowski, M. P. Kazmierkowski, S. Hansen, F. Blaabjerg, and G. D. Marques, "Virtual-flux-based direct power control of three-phase PWM rectifiers," IEEE Trans. Ind. Applicat., vol. 37, pp. 1019-1027, July/Aug. 2001.

[7] I. Agirman and V. Blasko, "A novel control method of a VSC without AC line voltage sensors," in Conf. Rec. IEEE-IAS Annu. Meeting, vol. 4, 2001, pp. 2175-2180.

[8] TMS320C24x DSP Controllers Peripheral Library and Specific Devices-Reference Set, vol. 2, Texas Instruments, Dallas, TX, Dec. 1997.

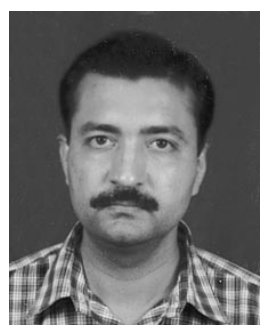

Souvik Chattopadhyay received the B.E. degree from Bengal Engineering College, Howrah, India, in 1988, and the M.Sc. (Eng.) and Ph.D. degrees from Indian Institute of Science, Bangalore, India, in 1990 and 2002, respectively.

$\mathrm{He}$ is currently an Assistant Professor in the Department of Electronics and Communication Engineering, Jalpaiguri Government Engineering College, Jalpaiguri, India. Between 1991-1995, he was with M/s Crompton Greaves Ltd., Bombay, India, as a Research and Development Engineer in the Power Electronics Group of R\&D (Electricals). Between 1996-1998, he was with M/s Cegelec India Ltd., Delhi, India, as a Project Engineer-Industrial Drives. He was a part of the commissioning team for phase IV modernization of the TISCO Hot Strip Mill, Jamshedpur, India. His research interests include design, analysis, control, and modeling of power converters for PFC circuits and active filter systems.

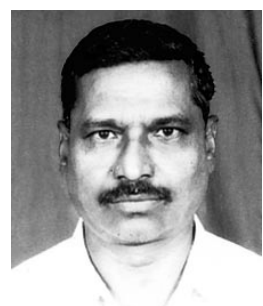

V. Ramanarayanan received the B.E. degree from the University of Madras, Madras, India, in 1970, the M.E. degree from Indian Institute of Science, Bangalore, India, in 1975, and the Ph.D. degree from California Institute of Technology, Pasadena, in 1986.

$\mathrm{He}$ is a Professor and Chairman of the Department of Electrical Engineering, Indian Institute of Science, Bangalore, India. He has held positions in industry as a Senior Design Engineer and Chief of R\&D with M/s Larsen and Toubro Ltd. (1970-1979) and NGEF Ltd. (1979-1982). His areas of interest are power electronics, industrial drives, switched-mode power conversion, and power quality issues. He is a Consultant to several industries in related areas. 